\title{
PROCURAÇÃO EM CAUSA PROPRIA
}

\section{É a procuração em causa propria meio habil para a transmissão de dominio?}

Não:

I — A procuração em causa propria não é meio habil para a transmissão do dominio.

Instituto engendrado pelos romanos pará ladear a difficuldade resultante da impossibilidade legal de se fazer cessão de obrigação pessoal sem o consentimento do devedor, (GAIO, Inst., II - $\oint \S 38$ e 39, UtP. fr. $25 \oint 2$, D. de usufr. ( 7 1), a procuração com a clausula in rem propriam investia o procurador do direito de tratar do negocio como coisa sua, podendo proceder contra o devedor em nome do mandante, e obter a solução da obrigação sem ter o dever de lhe prestar contas. (c. 6, Cad. de oblig. et act. (4-10), c. 1 C. de contr. jud. tut. (5 58) - Modestino fr. 76 - de solutionibus (46 5. -

E como, com a introducção el adopção do processo formular, foi permittido proceder-se em juizo por meio de representante, e este, - procurator ad litem, - ficava o senhor do processo (dominus litis) por effeito da litis con. testatio, sendo redigida em seu nome a condemnação (condemnatio), - c. 22 e 23 de procuratoribus (2-13) GAIO Inst. IV $\$ 86-$ ), acontecia que o mandato se tornava irrevogavel (NAMUR I $-\oint 233 \mathrm{n}^{\circ} 2$, MAYNZ II $-\oint$ 18). "Est et procurator in rem suam, qui scilicet negocia expedit non ad mandantis, sed propriam utilitatem" (VOET - Ad Pandectas - liv. III, tit. III n. $\left.{ }^{\circ} 8\right)$; "Non in alienam sed in suam rem procurator factus est". (ULP fr. 4. de re judic (42-1). 
"De nenhum modo é licita a revogação do mandato, se alguem foi constituido procurador em causa propria" (VOET - obr. cit. lib. III tit. III n. 23). Si dicat in rem suam se procuratorem datum et hoc probaverit, non debet carere propria lite. (ULPIANO, $25 \$ 2-d e$ procurat. et defens. (3-3). Procuratore in rem suam, dato, preferendus non est dominus procuratori in litem movendam, vel pecuniam suscipiendam: qui enim suo nomine utiles actiones habet, rite eas intendit (Id. fr. 55 h. t.). Sed si in rem suam datus sit procurator loco domini habetur: et ideo servandum erit pactum conventum. (PAULO fr. 13 $\$ 1-$ de pactis - 2 14). "Tale mandatum, diz CASAREGIS, re vocari non potest nec tacite per mortem, nec per expressam revocationem" (Disc. 3. $\left.{ }^{\circ}{ }^{\circ} 9\right)$.

II - A clausula in rem propriam, inserta na procuração, alterava, pois, a natureza das relações entre o mandante e o mandatario, porquanto, sendo da essencia do mandato que o mandatario preste contas ao mandante, aquella clausula o exonerava dessa obrigação e lhe permittia guardar como seu o valor recebido na acção promovida contra o devedor. Dahi a inferencia logica de que a procuraçäo em causa propria importa em uma cessão de direitos relativamente ao credor e ao procurador, ficando fóra do contrato o devedor; pois, se aquelle que é constituido mandatario, com tal clausula, recebe o negocio como seu, e delle trata no seu interesse, sem dar contas ao mandante, forçoso é concluir que os direitos do mandante foram, por essa forma, transferidos ou cedidos ao procurador. Chamava-se mesmo a isso miandare ou cedere actionem.

"Ainsi l'on avait trouvé le moyen de transférer à une autre personne, sinon le droit d'obligation même, au moins le résultat pécuniaire ou la valeur. de ce droit, sans avoir besoin de l'assentiment du débiteur et sans violer aucun principe ịuridique" (MAYYZ cit. $\$ 187$, pag. 79). 
"Un tale procuratore che viene in giudizio a nome altrui o a proprio vantagio dicesi procurator in rem suam, tale è il caso ch'io ceda altrui un credito ch'egli esigerà in mio nome in giudizio, per tenersi per lo quanto gli paguerà il debitore "GLucK - Alle Pandette, trad. ital. vol. III $\oint 396)$.

A inconveniencia resultante de não ser irrevogavel o mandato senão depois da contestação da lide, foi sanada com a opção, pela jurisprudencia, da notificação feita ao devedor (denunciatio debitori), que produzia o mesmo effeito da litis contestatio. (c. 4, quæ res pign. (8-17), c. 8, de novat. (8-42).

E tanto é verdadeira essa conclusạo, quanto é certo que os commentaidores em geral estudam a procuração em causa propria no capitulo em que tratam do instituto da cessão, e não no em que tratam do mandato (vide MAYNZ, II, §187, NAMUR, I, $\S .329$. Mas essa cessão é de tal maneira, dada a singularidade do meio por que é feita, que o procurador, só pelo facto de ser investido da prociração, não se póde proclamar dono da coisa a que se refere o mandato, nem a póde, consequentemente, alhear como coisa sua. Tuldo quanto tiver de fazer com respeito a ella ha e ser em nome do mandante. (1) Em nome deste póde alienal-a a terceiro; e, se quizer ficar dono da coisa, precisará adquirir elle proprio o dominio por qualquer dos meios de transmissão de propriedade que a lei reconhere, cumprindo todas as formalidades necessarias. A natureza da clausula in rem propriam permitte ao mandatario effectuar a transmissão do dominio para si mesmo, a despeito da regra geral que prohibe ao procurador adquirir para si a coisa objecto o mandato.

(1) Mackeldey observa que mais tarde foi permittido ao procurador actuar em seu proprio nome, por meio de uma actio utilis. (Droit Bomain \& 369). 
Nem se objecte que não poderá o procurador transmittir a cousa a si mesmo porque na escriptura não se apresentarão duas pessoas comparecendo uma como outorgante e outra como outorgada.

A objecção é imprecedente, porque na doutrina juridica romana nunca foi contestada a regra de que um só homem póde conter em si a investidura representativa de diversas pessoas, regra que ficou crystalizada na concisa frase de CICERO - unus homo multas personas sustinere potest. E assim foi sempre praticado em Roma, como se vê, por exemplo, no $\oint 4$ das Inst. - de inof. test. ( 18), onde se permitte ao tutor, cujo pai deixou em testamento um legado ao pupillo, aceitar o legado em nome deste, e querelar, elle proprio, de inofficioso o testamento paterno; e como se vê tambem no fr. 3 - de adopt et emanc. (1 7), onde está reconhecido que um filho-familias, que fosse consul ou presidente de provincia, podia confirmar, elle proprio, a sua emancipação ou adopção.

III - O direito moderno adoptou o instituto da procuração em causa propria assim como veiu de sua fonte originaria, que foi o direito romano. "Malgré la règle que le mandat ne saurait concerner le seul avantage du mandataire, on reconnait en droit des procureurs appellés procuratores in rem suam, qui agissent pour leur propre utilité, et non pas pour l'utilité du mandant. Ce sont ceux qui se sont fait céder les actions de quelqu'un et procèdent sous son nom ou à sa place dans leur propre intérêt. TROPLONG. Dú mandat, n. ${ }^{\circ} 37$. Neste caso, o mandato é irrevogavel. (Id. n. ${ }^{\circ} 718$ ).

THEOPHILE HUC, tratando de precisar o significado das expressões mandato e procuração, faz estas in teressantes consideraçóes: Se é verdade que todo mandato, isto é, todo poder de agir implica procuração, isto é, poder de representar, a reciproca, entretanto, não é verdadeira. A procuração, ou, em outros termos, o poder de representar uma pessoa, não implica necessariamente um 
mandato, isto é, o poder de agir por conta dessa pessoa. Assim, por exemplo, acontece muitas vezes que o titular de um credito quer transferil-o a uma outra pessoa por causa de venda, liquidação deı contas, acção de pagamento, ou qualquer outro motivo. Em logar de se conformarem com as regras estabelecidas para o transporte - cessão, as partes interessadas se limitam a redigir um escripto particular estipulando o accordo. O titular do credito, para pôr a outra parte em condições de se utilizar em seu proveito do credito cedido, dar-lhe-ái uma procuração, isto é, um poder de o representar com relação ao exercicio do direito cedido. Em face de terceiros o procurador agirá como um mandatario, representando o sujeito originariamente investido do credito cedido. Mas em suas relaçóes com o representado, o procurador não deverá ser tratado como um mandatario, pois, em realidade, não houve mandato, e por consequencia, não haverá obrigação de prestar contas, sendo elle apenas procurador em seu interesse pessoal - procurator in rem suam - como ser dizia em direito romano. (Code Civil - vol. 12 n. 3 ).

IV - Para o direito portuguez passou o instituto, sendo adoptado com as mesmas linhas geraes conforme as traçou o direito romano. A Ord. liv. 3 tit. $45 \S 7$, o reconheceu referindo-se expressamente ao "procurador em causa sua propria", a quem diz que "pertence todo o proveito e damno da demanda por ser obrigado a compor o vencimento della"

Nesse sentido SYLVA, ad. Ord. liv. 3 tit, 20, pr. n. ${ }^{\circ} 16$, definiu: - "Procurator in rem propriam est id, qui sibi debet applicare commodum actionis mandato et ad propriam utilitatem negotium administrat.

"A clausula, inserta na procuração, de que o procurador administrará o negocio como causa sua, ou in rem propriam, como orldinariamente se costuma", ensina COELHO DA ROCHA, inverte a natureza deste contrato, importa cedencia gratuita ou onerosa, conforme é feita 
por liberalidade ou com retribuição. Por isso, tal procuração: $1 .^{\circ}$ não acaba pela morte de qualquer das partes; $2 .^{\circ}$ nem pode ser livremente revogada pelo constituinte; $3 .^{\circ}$ como o procurador adquire direito ao objecto sobre que versa a procuração, não fica sujeito a dar contas; 4. pode praticar todos os actos relativos ao negocio, sejam, ou não, comprehendidos na procuração". ( $D i$ reito Civil, vol. $2 .^{\circ}$ n. ${ }^{\circ} 799$; GUERREIRO, Tr. 4 L. 6 cap. 2 n. 116).

Segundo doutrina CORREA TELLES, "aquelle que é constituido procurador in rem propriam subentende-se cessionario do direito e acção do constituinte - Dig. Port. III n. 651 .

"Em nosso velho direito, observa DIAS FERREIRA, era tambem conhecida a procuração com a clausula in rem propriam, improłpriamente chamada procuração, porque importava uma verdaideira cessão de direitos. Neste documento bem podia dizer-se que não havia mandante e mandatario, mas sim cedente e cessionario, pois que o mandato não terminaria pela morte de nenhum dos pactuantes, o que é incompativel com a natureza deste acto juridico, (art. 1363). O codigo, pois, com razão não reconhece entre as formas do mandato um titulo ou acto juridico, que está subordinado ás regras da cessão dos direitos" (Cod. Civ. Port. annot. art. 1325).

$\mathrm{V}$ - No direito patrio, a procuração em causa propria foi sempre recebida e praticada. RAMALHO, em uma de suas lições proferidas no anno de 1865, explicou desenvolvidamente o significado da procuração em causa propria. Procurador em causa propria, dizia elle de accordo com o Compendio adoptado na Faculade de Direito de S. Paulo, é aquelle que trata de negocios por utilidade propria e não do mandante. Isto se verifica, em geral, todas as vezes que alguem tem cedido ¿direitos a outrem e dá uma procuração ao cessionario para, em nome do cedente, tratar de um negocio; ha, pois, - procuração - porque se usa do 
nome do constituinte, e se diz - em causa propria - porque o negocio é do procurador. Quando alguem constitue um procurador, accrescenta o notavel jurisconsulto, e o declara em causa propria, entende-se que elle transferiu o seu direito sobre o objecto para o procurador, mas que este deve, para tornal-o effectivo, usar do nome do cedente.

Em sua Praxe Brasileira o douto Mestre ensina que "a procuração, concedida com a clausula de que o procurador administrará o negocio como cousa sua, importa cedencia gratuita ou onerosa, e, por isso, segue-se: $1 .^{\circ}-$ que não acaba com a morte de alguma das partes; $2 .^{\circ}-$ não póde ser livremente revogada pelo constituinte; $3 .^{\circ}$ - não fica o procurador obrigado a prestar contas, podendo praticar todos os actos relativos ao negocio, como é permittido áquelle que tem procuração especial, e até transigir, porque lhe diz respeito o commodo ou prejuizo da acção commettìda, e é tido em logar do constituinte" (Praxie, 2. ${ }^{\mathrm{a}}$ ed. $\S 61$ ).

CARLOS DE CARVALHO assim consolidou o direito positivo vigente em 11 de agosto de 1899: "Si ao mandatario pertencer toło o proveito e damno do mandato, será considerado procurador em causa sua propria (in rem propriami)", e essa procuração póde operar desde logo trans. missảo de propriedade" (Nova Consolidação, art. 1339 e §̣ unico).

DUARTE DE AZEVEDO, em luminoso parecer publicado, assim se manifesta, referindo-se ao direito romano: "Como se vê, o procurator in rem suam não era um mandatario, visto como este obra em nome e no interesse do mandante. Era procurador apenas no modo ápparente de funccionar, porque exercitava os direitos e acçóes do credor; mas na realidade era cessionario de taes direitos e acções, porque procedia no seu exclusivo interesse, fazendo proprias todas as vantagens do credito. Eis a razão por que DONEAU não considera o caso como de mandato: neque enim hic versatur vere mandatum - procurator rem 
suam gerit, non alienam, quod longè recedit à vero mandato, in quo res aliena geritur (DON. liv. IV cap. $44 \mathbf{n} .^{\circ}$ 16. Veja-se PAUL GIDE - Du Transpòrt des créances, cap. III 3). E' precisamente esta a noção que, no direito patrio, temos da procuração in rem propriam. Não ha duvida que essa forma de cessão é excusada no direito moderno, em que a cessão dos creditos, de modo directo, é francamente permittida. Porém a tradição do direito mantém o antigo expediente, como tantas vezes acontece com os institutos juridicos; e pela pprocuração in rem propriam, quando devidamente solemnizada, supõe-se sempre feita a cessão do crédito, e até mesmo a alienação da propriedade, se esta fôr o objecto da procuração. Decr. 3363 de 5 de agosto de 1899, tab. III n. 51 (Controversias Juridicas, cons. XXIV pag. 133).

MUNIZ BARRETO, relator do accordam do Conselho do Tribunal Civil e Criminal do Districto Federal, de 25 de agosto de 1904, assim escreveu: "a procuração in rem propriam é um dos meios por que se opera a cessão: não acaba pela morte de qualquer das partes; não póde ser revogada; e o procurador não fica obrigado a contas. E' reconhecido em nosso direito, e lhe faz referencias o regulamento annexo ao decr. n. 3564 de 22 de janeiro de 1900, que exige, como o de 11 de janeiro de 1903, sello proporcional nas procurações com a clausula in rem prapriam. Della tambem trata o Regimento de Custas da Justiça do Districto Federal" (Direito, vol. 96 p. 292). E como relator do accordam da 2. ${ }^{a}$ Camara da Côrte de Appellação, de 9 de Junho de 1905, disse mais: "sem embargo da sua origem historica, do motivo juridico da sua creação, a procuração in rem| propriam é ainjla admittida de modo inilludivel pelo nosso direito, constituino uma das formàs por que se opera a cessão de creditos"... "As nossas leis, tanto antigas como modernas, abstrahindo daquella circumstancia peculiar ao direito romano, admittem essa forma especial de cessão, a par do contrato regular, em que de- 
vem concorrer todos os elementos ssenciaes da compra e venda, se a transmissão do crédito é a titulo oneroso, ou da doação, se é a titulo gratuito. Ao procurador em causa propria se refere a Ord. do liv. $3 .^{\circ}$ tit. $45 \S 7^{\circ}$ Della tratam os civilistas, dizendo que, não é revogavel, nem expira pela morte do mandatario, que não fica obrigado a contas" - "Quando commentam a Ord. do liv. 3: ${ }^{\circ}$ tit. 27 $\oint 2 .^{\circ}$, nossos praxistas a dão como existente no direito patrio" "Modernamente vemol-a reconhecida, com todas as suas prerogativas juridicas, no decr, $n .^{\circ} 771$ de 24 de setembro de 1890, expedido pelo Governo Provisorio, e bem assim no regulamento do sello, annexo ao decr. n. ${ }^{\circ}$ 3564 de 22 de Janeiro de 1900, e no regulamento de custas judiciaes. Entretanto, é condição essencial, para que produza os necessarios effeitos, que do respectivo instrumento conste o valor ou o preço da cessão, sujeita a sello proporcional. Não basta, porém, a mera existencia dessa procuração revestida de todas as formalidades legaes, e ainda que em instrumento publico, para que o devedor cedido fique obrigado a pagar ao cessionario, em logar de desobrigar-se do cedente. Attenta a natureza da cessão dè credito, em que o devedor não figura como parte contratante, a doutrina e a legislação dos povos cultos exigem a formalidade da denunciatio, instituida pelo direito romano.ou, pelo menos, prova de que o devedor teve conhecimento da cessão, para que lhe não aproveite a boa fé e elle não possa oppor ao primeiro cessionario o pagamento feito a cedente ou a cessionanio posterior. Notificado da cessão, o idevedor, que procede fóra dos termos della, não se exime da responsabilidade perante o cessionario. Se conhece a cessão, embora não notificado, e, sem embargo, paga ao cedente, que elle bem sabia não ter mais direito, commette uma fraude, e, por isso, não se desonera da obrigação para com os cessioanarios. Outrosim, é preciso que o devedor tenha conherimento da cessão em sua integridade, ou, pelo menos, em seus termos essenciaes, para que possa 
agir com segurança em face do proprietario actual e não venha a soffrer em sua fortuna" (Direito, vol. 98, pag. 127).

MONTENEGRO, relator do accordam da 1. Camara da Côrte de Appellação, de 18 de Junho de 1906; diz que a procuração in rem propriam é "forma particular da cessão ou venda dos creditos, cuja tradição por ella se opera, adquirindo o cessionario comprador os direitos que tinha o cedente vendedor, sobre a cousa cedida, e por esse mandato especial lh'os transfere, liberando-o, por esse meio, da ogrigação de rem prestare, que é a primordial do con. tracto" (Direito, vol. 100 pag. 560).

PIRES DE ALBUQUERQUE, em sentença proferida como juiz federal em. 25 de agosto de 1909, adverte que é impossivel contestar á procuração em causa propria, "e jamais lhe foi contestado, o effeito de transferir creditos, uma vez que satisfaça ás condições postas pela lei como requisitos substanciaes desta transferencia: - a insinuação, se se trata de simples liberalidade; o consentimento, o preço e a cousa, se se trata de venda" (Direito, vol. 110 pag. 42).

EPITACIO PESSOA, em parecer publicado no Jornal do Commercio de 25 de junho de 1916, assim se exprime: "A procuração em causa propria, corruptela de um instituto analogo de Direito Romano, está, apezar de não subsistir mais a razão juridica de sua instituição, admittida em nossas leis". Segue-se a citação das leis, autores e sentenças. "Uma vez satisfeitas as exigencias legaes, como occorre no caso sujeito, isto é, a declaração do preço e o pagamento do sello, a procuração in rem suam é um titulo legitimo de cessão de direito. Ora, a cessão, segundo o seu moderno conceito, não confere simplesmente ao cessionario a qualidade de representante do cedente ou o mero exercicio do direito deste, mas desloca desde logo de um para outro todo o direito a credito cedido. (LACERDA DE ALMEIDA, Obrigações, $\S 31$ ). Na procu- 
ração in rem propriam, portanto, o chamado mandatario não age em nome e no interesse do mandante, como é da essencia do mandato, mas em seu proprio nome e utilidade: "Procurator rem suam gerit, non alienam" (Revista dos Tribunaes, vol. 18, pag. 192).

LAFAYETTE, em parecer publicado no $O$ Direito vol. 87 , pag. 24 , com data de 20 de maio de 1899 , diz que a clausula in rem propriam, usada nos instrumentos de mandato, não induz no Direito Moderno, a cessão ou transferencia do direito ou cousa a que se refere o mandato, mas tão somente a concessão ao mandatario de poderes illimitados, tendo havido julgados nesse sentido entre nós. Accrescenta que, desapparecida a causa que determinou a creação do instituto do direito romano, perdeu elle a sua razão de ser, e tal procuração só continuou a ser usada como significando, em uma forma abreviada, a concessão de plenos e illimitados poderes; jamais póde operar concessão ou transferencia do direito ou cousa, se não especificar a cessão com os requisitos legaes, a qual, se for gratuita, será reputada doação, e se por titulo oneroso, valerá como compra e venda, devendo conter, em ambos os casos, os requisitos essenciaes destes contractos. Assim, pois, conclue elle, a simples declaração de que o procurador é constituido in rem propriam não vale como cessão, porquanto falta no titulo a designação do preço, para valer como venda, e a formalidade da insinuação, quando exceder á taxa da lei, (no direito anterior) para valer como doação.

Com esse parecer concordou RUY BARBOSA, $n$ ? mesmo volume do $O$ Direito, á pag. 26 ; e a doutrina patrocinada por tão eminentes autoridades tem sido a'doptada por varios jurisconsultos patrios, dentre os quaes merece menção especial o snr. ministro EDMUNDO LINS, como relator do accordam n..$^{\circ}$ 2.977, de 3 de setembro de 1919, publicado na Revista do Supremo Tritunal, vol. 22, pag. 189. 
Mas LAFAYETTE, em parecer posterior, datado de 9 de dezembco de 1905, assim se exprime: "O contracto contém expressa a clausula de procurador "em causa propria", in rem suam. Esta clausula tem, como é sabido, duas significações, a saber: ou , importa simplesmente a concessão de poderes illimitados ou cessão de $d i$ reito. Quando tal clausula importa cessão, o cessionario se torna dono do negocio e não está obrigado a dar contas ao cedente" (Pareceres - vol. 1. $0^{\circ}$ pag. 74).

Por ahi se vê que, segundo o saudoso jurisconsulto, a procuração em causa propria podia significar algumas vezes simples 'concessão de paderes illimitados, outras vezes cessão de direitos.

VI - Qual o criterium para se poder precisar o seu significado, determinar-lhe os effeitos?

Estudando-se os casos sobre os quaes foram emittidos os dois; alludidos pareceres, conclue-se que as procurações em causa propria foram julgadas como simples mandatos com poderes illimitados, porquer os respectivos procuradores não pagaram preço algum aos mandantes, e, para que haja cessão, equivalente á venda, é essencial o pagamento do preiço. Tambem não houve insinuação, e para que a cessão valesse como doação, era necessaria, nesse tempo, essá formalidade, quando o valor do objecto excedia á taxa da lei.

Então o criterio para poder dizer-se que uma procuração em causa propria tem o effeito de cessão de direitos é esse, de ha muito fixado pelo velho CORREA TELLES: - o pagamento do preço, se se trata de cessão onerosa, equivalendo a compra e venda; a insinuação, se se trata de cessão liberal, equivalente a doação de cousa de valor acima da taxa da lei (Digesto Portuguez n. ${ }^{\circ} 651$, I, III).

VII - Como em nosso direito civil actual não é mais exigida a formalipdade da insinuação para a validade 
das doações, segue-se que, outorgada a alguem uma procuração em causa propria sem que o procurador effectue qualquer pagamento, a procuração opera a transferencia dos direitos pessoaes valendo como doação, a qual, só terá efficacia jurdica se não houver violação de qualquer dis. posição legal concernente a esse contrato.

Se a outorga for feita mediante pagamento de preço, opera-se tambem a transferencia dos direitos pessoaes do outorgante ao outorgado, valendo a procuração como uma compra e venda de direitos.

Essa transferencia de direitos, operada pela procuração em causa propria, quer valendo como doação, quer valendo como compra e venda, não envolve a transmissão de dominio. Para que se dê esta transmissão, é essencial que no respectivo instrumento conste declaração expressa nesse sentido; que seja elle feito por escrptura publica, quando se referir a immovel de valor superior a um conto de reis, devendo ser feita a transcripção no competente registro, conforme as exigencias do Codigo Civil, e ficando o outorgado sujeito ao pagamento do devido imposto de transmissão de propriedade. Praticadas essas formalidades, não ha duvida que o acto juridico nem pode ser considerado um simples mandato em causa propria, mas uma verdadeira doação, ou compra e venda, conforme o caso. Quando, porém, taes formalidades não são observadas na outorga de poderes em causa propria, o instrumento, publico ou particular, não deixa de ter pleno valor como um mandato in rem propriam, e, como tal, opera a transferencia irrevogavel de direitos pessoaes ao procurador, que tem a faculdade de os exercer em toda a sua plenitude, em nome do mandante, podendo mesmo dispor delles transmittindo o respectivo dominio a quem quer que seja, sem obrigação de prestar contas ao mandante. Nem ha impedimento em ser o dominio transmittido ao proprio procurador, visto que seı trata de procuração em causa 
propria, isto é, propositadamente outorgada em beneficio seu.

VIII - As leis brasileiras reconheceram a legitimidade da procuração em causa propria designando-a com o mesmo nome com que veiu dos romanos - in rem propriam, e não foi senão por a considerarem como um titulo de ces. são de direitos, que a sujeitaram á taxa do sello proporcional, significando, por essa forma, que não a equiparavam a um simples mandato com poderes illimitados (Reg. do Sello - Decr. n. ${ }^{\circ} 3564$ de 22 de janeiro de 1900, tab. B $\oint 4 .^{\circ}$ n. 9 ; Lei n..$^{\circ} 3966$ de 25 de dezembro de 1919 , tab. B $\oint 4 .^{\circ}$ n. 9 ; Lei 4984 de 31 de dezembro de 1925 , art. 11; Dec. n. 17538 de 10 de novembro de 1926, Tabella $\mathrm{B}, \S 4 .^{\circ}, \mathrm{n} .^{\circ} 10$ e nota $4 .^{\mathrm{a}}$.

O Decr. $n .^{\circ} 3363$ de 5 de agosto de 1899, estabelecendo as custas devidas pelos actos dos tabelliães no Districto Federal, determinou que lhes coubessem custas eguaes ás das escripturas, "sendo procuração em causa propria, que opere desde logo a transmissão de propriedade do mandante para o mandatario" (Tabella III n. 51 letra d) ) v. decr. . $^{\circ} 771$ de 24 de setembro de $1890 \mathrm{rt.} 4$, decr. n. 2573 de 1897 , tab. B $\oint 4 .^{\circ}$ n. $^{\circ} 8$.

IX - Em nosso direito actual ella existe em virtude da disposição expressa do art. 1317 do Cod. Civil, que lhe reconhece o caracter de, irrevogabilidade.

$E$ se a lei the reconhece a existencia, sem lhe fazer alteração alguma, é porque quiz admittil-a como veiu do direito romano e tal como foi sempre recebida e praticada pelo direito patrio e pelo costume. Assim, em que pese á opnião em contrario de CLOVIS BEVILAQUA, manifestada ao commentar o referido art. do Cod. Civil, a verdade é que não se póde deixar de affirmar que a cessão de direitos pessoaes é um dos effeitos da procuração em causa propria, tanto mais quanto é o mesmo CLOVIS quem sustenta que tal mandato é irrevogavel, e que o mandatario não tem que prestar contas da sua gestão ao mandante. (Comment. vol. 5. pag. 65). 
$\mathrm{X}$ - Do exposto, e em face do Codigo Civil, se podem tirar as seguintes conclusóes:

1. $\left.{ }^{2}\right)$ A procuração em causa propria importa em cessão ou transferencia de direitos pessoaes (obrigações ou acçóes).

2. ${ }^{a}$ ) Contém poderes illimitados.

3. $\left.{ }^{\mathrm{a}}\right) \quad \mathrm{E}^{\prime}$ irrevogavel.

4. $\left.{ }^{a}\right)$ Não se extingue pela morte de qualquer das partes.

5. ${ }^{\mathrm{a}}$ ) $\mathrm{O}$ mandatario não é obrigado a prestar contas ao mandante.

6.") $O$ mandatario deve actuar em nome do mandante.

$7^{a}$ ) Póde ser substabelecida desde que o seja. sem reserva de poderes.

8. ${ }^{a}$ ) Pódde ser feita por escripto particular revestido das formalidades legaes.

9. ${ }^{\mathrm{a}}$ ) Está sujeita ao sello proporcional.

10. $\left.{ }^{a}\right)$ Não é titulo habil para a transferencia de dominio ou de direitos reaes.

11. ${ }^{a}$ Quando a procuração em causa propria é outorgadda para a alienação de moveis ou immoveis, o mandatario fica investido de poderes irregogaveis para alienar tae cousas a si mesmo ou a terceiros, fazendo, como representante do mandante, a transmissão do dominio, sem ficar obrigado a lhe prestar contas.

12. ${ }^{\mathrm{a}}$ ) Se antes de haver o procurador em causa propria operado a transmissão do dominio, por forma legal, o mandante alienar a mesma cousa a outrem, fica o adquirente legitimo senhor da cousa, porque a adquiriu de quem tinha dominio sobre a mesma, salvo ao mandatario o direito de haver perdas e damnos do mandante.

S. Paulo, julho de 1927.

Reynaldo Porchat. 